\title{
Sobre la historia de los estudios sociolingüísticos en España (castellano y catalán)
}

\author{
FRANCISCO ABAD
}

Cátedra de «Lengua Española» (4. ${ }^{\text {a }}$ cátedra).

UNED

A)

Esta primera y breve Nota se halla dedicada a indicar algunos de los primeros pasos de los análisis sociolingüísticos entre nosotros, en referencia al castellano y al catalán; llegamos nada más que hasta los primeros años setenta, en que se creó una conciencia de la materia que luego ha resultado decisiva.

Entre las primeras alusiones que se han hecho en los estudios filológicos españoles - en efecto- a la estratificación social del lenguaje, se encuentran las de García de Diego. Sabido es que don Vicente, aunque un poco al margen de lo que estaba argumentando, manifestó al ingresar en la Academia Española que el lenguaje no es «la unidad artificiosa de la lengua oficial, sino [...] una vastísima complejidad de dialectos mútuamente influídos y [...] una superposición de dialectos sociales», y concluía en tanto postulado de método: «Es pues un absurdo soñar con la uniformidad, si una lengua es intricado polimorfismo» (Problemas etimológicos, Ávila, 1926, p. 23).

Está por rastrear en los sucesivos escritos de este autor cuántas veces hizo alusión a los que él mismo denominaba - de acuerdo con algún antecedente«dialectos verticales»: corresponde a los especialistas establecer la historiografía del concepto (y la expresión) dialectos verticales en Vicente García de Diego, quien tampoco olvidó referirse a lengua culta y lengua vulgar (Lecciones de lingüística española).

Puede comprobarse por ej. cómo en la primera edición del Manual de Dialectología española (Madrid, Cultura Hispánica, MCMXLVI) de nuestro autor no aparece un párrafo que sí se encuentra en la segunda (1959), y que dice: «Son dialectos verticales las modalidades estables de las hablas de las distintas clases sociales»: habla vulgar, hablas técnicas, jergas, ... (se halla recogido en $F$. Abad, ed., Lecturas de Sociolingüística, pp. 31-42).

Pero si hacemos al menos una cala en su Lingüística general y española (Madrid, CSIC, 1951, aunque premiada ya en 1949), encontramos que García de Diego ya había anticipado el anterior pasaje del año 59 con este enunciado: 
Se ofrecen en la lengua las variantes de los distintos estratos sociales y de los distintos grupos de la actividad humana, de las distintas profesiones y oficios, de las distintas edades y sexos, y de las variantes jergales [...]. Así bajo la unidad aparente de una lengua se nos ofrecen en una investigación atenta todas las antinomias regionales y sociales de los distintos grupos que integran la nación.

La partición social de una comunidad hablante lleva a su partición idiomática: la lengua no es uniforme ni monolítica, proclamaba una vez más nuestro autor antes de que esta tesis quedase universalmente difundida en algunos escritos de Jakobson que la recordaban.

Don Vicente veía perfectamente que la esencia de lo idiomático es dialectal, que estamos siempre ante códigos comunicativos lo suficientemente uniformes como para permitir la intercomprensión, pero que se hallan siempre internamente escindidos -aunque sea subfuncionalmente-, dialectalizados, diversificados. De ahí que se expresase de esta manera:

Las lenguas son dialectos y los dialectos son lenguas [...]. La lengua es un dialecto que ha llegado a emanciparse. Lengua es todo grupo lingüístico con gran diferenciación formal de otras.

Efectivamente la lengua nada más se diferencia del dialecto en que se halla muy diferenciada de otros códigos, estandarizada o nivelada, con tradición literaria, etc.

En las condiciones de los años cuarenta en que escribía, García de Diego mantuvo que «las diferencias de la actividad vital entre hombres y mujeres imprime una diferencia trascendental de su vocabulario», y justamente esto es lo que comprobó que ocurría Manuel Alvar en las «Diferencias en el habla de Puebla de Don Fadrique (Granada)» que advirtió ( $R F E, \mathrm{XL}, 1956$ ).

Señalaba así este dialectólogo el arcaísmo de algunos de los rasgos del habla de las mujeres «en la conservación de la $l l$ y de la $-s$ final absoluta, en el mantenimiento de unas formas verbales perdidas ya en el habla de la gente de cultura media, y en algunas voces de difusión provincial». Los hombres por contra resultaron innovadores en el yeísmo, con la $-s$ final absoluta aspirada, con su léxico de carácter más general y actualizado, con formas verbales modernizadas, ...; no obstante el habla femenina asimismo mostró algún rasgo de modernidad. La situación idiomática quedaba matizada por nuestro autor, que en todo caso investigaba lo sociolingüístico.

Por ej. también Dámaso Alonso, Alonso Zamora y María Josefa Canellada, al hacer con anterioridad un análisis del habla de la ciudad de Granada (NRFH, IV/3, 1950), llevaron a cabo observaciones que están referidas «a distintas capas sociales o culturales», y así testimoniaron cómo «el seseo pertenece a hablantes más ilustrados o de condición social más elevada» que el ceceo; literalmente hablaron además de «la penetración del sentido vertical de [algunas características ...] del habla popular en las clases superiores de la pronunciación granadina». Las presentes advertencias creemos que han pasado inadvertidas, pero en justicia deben recordarse al trazar la trayectoria de la sensibilidad sociolingüística entre nosotros. 
Estamos seguros de que empezando por Menéndez Pidal y Amado Alonso, la lectura de nuestros clásicos lingüísticos ilustrará bien la presencia de esa sensibilidad sociolinguística aludida en diferentes autores que hasta ahora desconocemos quizá - en parte - en tal faceta (de memoria recordamos alusiones juveniles pertinentes por parte de Diego Catalán y de Álvaro Galmés, etc.).

En lo que respecta a don Amado cabe destacar que al ocuparse de la pronunciación dialectal de $\operatorname{tr}(1925)$ acompañó las observaciones geográficas de otras sobre su realidad social estratificada; poco tiempo más tarde, al escribir nuestro autor las ciento cincuenta páginas de sus «Problemas de dialectología hispanoamericana» (Buenos Aires, Facultad de Filosofía y Letras, 1930), trataba de determinado fenómeno fonético e indicaba para cada geografía del mismo su «estado social», es decir, su vigencia según los distintos colectivos de hablantes: reseñó así el respectivo «alcance social» de determinadas pronunciaciones. Estamos en este caso ante una amplia monografía juvenil aún, pero muy lograda.

En fin los capítulos recogidos en La Argentina y la nivelación del idioma (Buenos Aires, Institución Cultural Española, 1943), no están referidos a cuestiones sociolinguísticas, a la incidencia de lo social en lo idiomático, pero sí en algunos momentos a lo que de manera más amplia pueden llamarse relaciones entre lengua y sociedad. Etc.

$$
\text { *** * }
$$

Según nuestra percepción alcanzó una importancia decisiva el trabajo de José Pedro Rona, Algunos aspectos metodológicos de la dialectología hispanoamericana (Montevideo, 1958); no era autor español, pero sí lingüista de nuestro idioma, y el presente escrito creemos nosotros que pesó en autores como Manuel Alvar, quizá el mismo Diego Catalán, etc.

Para lo que ahora nos importa, Rona decía en un párrafo de importancia:

A cada fenómeno comprobado en el habla de determinada capa socio-cultural de cierto lugar pueden asignársele dos valores diferentes. En comparación con los fenómenos de otras capas socio-culturales del mismo lugar, la diferencia es de nivel. En comparación con el habla de niveles iguales de otros lugares, la diferencia es dialectal.

Quedaba establecida pues de una manera completamente explícita la necesidad de analizar los «niveles socio-culturales» de un hablar, programa que el lingüista uruguayo delineaba así:

La distinción entre niveles se basa en la proporción de características diferenciadoras y de características comunes. Se trata, en realidad, de una especie de isoglosas entre las distintas capas sociales, que podrían denominarse «isoglosas verticales».

Y añadía a pie de página nuestro autor que «las isoglosas «verticales» serían entonces diastráticas»; ejemplificaba además otra vez en el texto con que las iso- 
glosas verticales «del tipo haya:haiga son las que definen los distintos niveles cuando forman haces», al igual que ocurre con los dialectos espaciales o geográficos.

Creemos que afirmaciones como las presentes son las que se encuentran en el origen del propósito de Manuel Alvar de hacer en efecto una monografía sobre los «Niveles socio-culturales en el habla de Las Palmas de Gran Canaria», y con toda probabilidad dejaron asimismo una huella en las anteriores páginas de Diego Catalán «El español en Canarias» (1963), que constituyeron su ponencia en la Asamblea de Filología del I Congreso de Instituciones Hispánicas cuyas Actas se publicaron con el título de Presente y Futuro de la Lengua Española.

$* * *$

No obstante, al informar años antes (1959) acerca de Los nuevos atlas lingüísticos de la Romania (Universidad de Granada, 1960), Manuel Alvar hacía algunas observaciones sociolingüísticas, y relataba en efecto: «El descubrimiento de una clara oposición hombre/mujer en la primera de mis encuestas [del $A L E A]$ fue la feliz casualidad que me llevó a introducir este aspecto de sociología lingüística en mi Atlas. Así hemos podido ver en muchos casos la diferencia articulatoria entre gentes de sexo distinto y, sobre todo, el arcaísmo femenino en ciertas zonas fronterizas» (el caso ya aludido de Puebla de Don Fadrique).

El mismo autor informaba de que en las capitales de provincia andaluzas se interrogó en el $A L E A$ «cuando menos, a dos personas universitarias (hombre y mujer) y a otras dos (también de sexo distinto) de barrios diferentes», con lo que quedó mostrada la «preocupación por algunos hechos de sociología lingüística».

Esta sociología lingüística o sociolingüística despuntaba ya en los estudios geográfico-linguiísticos, sin duda por la impronta principal de K. Jaberg y de otros romanistas.

$$
* * *
$$

En la mencionada Asamblea de Filología del I Congreso de Instituciones Hispánicas, el prof. Catalán - recogido en abreviatura - hacía notar el olvido en que se dejaba «la muy importante estratificación de la sociedad en niveles lingüísticos varios», y en referencia a Canarias (y a América) enunciaba:

Dentro de los centros urbanos la sociedad se articula en grupos varios, vital y culturalmente diferenciados, que se gobiernan por ideales lingüísticos divergentes; aunque desde luego nunca lleguen a establecerse entre los varios estratos sociales «fronteras lingüísticas» precisas, comparables a las que en un viejo dialecto pueden dividir espacialmente el habla de dos comunidades contiguas.

La Dialectología ya - y al margen de las anticipaciones de García de Diego, ...-, se hacía asimismo Sociolingüística. Creemos que las fechas nos indican que verosímilmente Rona actuó de estímulo para Catalán, y ambos lo resultaron para Alvar. 
En 1966, el prof. Diego Catalán insistió otra vez en que «las distintas variedades del español que existen en Canarias no son el resultado de evoluciones divergentes de la lengua ocurridas en las varias islas o en diferentes comarcas de una isla, sino que representan estratos superpuestos de español atlántico, que afloran aquí y allá según el nivel socio-cultural de los hablantes» («El español en Tenerife», $Z R P h, 82$ ).

Una polémica entre Catalán y Alvar a propósito de estas cuestiones la hemos reseñado ya nos parece que un par de veces. Alvar la expuso en el mismo tomo 82 de la $Z R P h$ (de su artículo han de verse especialmente los $\S \S 3 ; 4 ; 5 ; 14$; $15 ; 34)$, y la recogió luego en otra versión en Estudios canarios (I, Cabildo Insular de Gran Canaria, 1968), y al propósito escribía con alcance general:

Un hablante, por pertenecer a un nivel determinado (campesino, obrero, intelectual, etc.), ya nos está dando materiales sociológicos [...]Un mismo rasgo afecta a clases sociales distintas, aunque otros independicen a los grupos de hablantes de grupo social diferente. [...] Será necesario el estudio de los distintos estratos sociales para conocer los «dialectos verticales» [... Es cierta] la existencia de niveles socio-culturales en las Islas [...] La sociología lingüística es necesaria para una apurada visión de los hechos dialectales (pp. 25-41).

Nos parece muy nítida la impronta en las presentes consideraciones del planteamiento que queda visto de José Pedro Rona.

En el panorama «Estado actual de la dialectología románica» que le fue encargado (1968), el propio Manuel Alvar pudo decir que «un inventario de todas las capas previsibles [...] permite - en la comparación de los estratos- analizar lo que pudiera ser una estilística del habla (de acuerdo con cada una de las capas) y, desde ella, una estilística de la lengua (como modalidad que afecta a todas ellas)» (cfr. Estructuralismo, geografía lingüística y dialectología actual, Madrid, Gredos, 1969).

De esta manera se llegará así al libro monográfico de nuestro autor y que ya hemos aludido, Niveles... (1972).

Niveles socio-culturales en el habla de Las Palmas de Gran Canaria consta de cuatro partes, que nos parecen inspiradas bastante aproximadamente en las mismas cuatro de que a su vez consta el libro de don Ramón Orígenes del español: datos documentales; análisis lingüístico; conclusiones del análisis anterior; conclusiones teóricas. Con posterioridad, el prof. Manuel Almeida ha vuelto a hacer el análisis diastrático de El habla de Las Palmas de Gran Canaria (Cabildo Insular de Gran Canaria, 1990), y su trabajo rectifica en parte el de Alvar.

Don Manuel Alvar se remite de manera expresa a J. P. Rona, y expone que ciertamente se encuentra haciendo un análisis de lo que él Ilama bien Sociolingüística o Lingüística social; proclama la pertinencia científica de los análisis idiomáticos diastráticos, y enuncia:

Nos encontramos pues que frente a la dialectología — diatópica- vamos descubriendo una serie de estratos que permiten hablar de una dialectología vertical o diastrática. Producida - en nuestro caso concreto- por esas oposiciones 
campo ciudad y, dentro de ésta, niveles sin cultura -con estudios elementales - con estudios medios y superiores [...]. Entonces - vemos - aparece una dialectología vertical de la que se ha hablado hace mucho tiempo $(\S 80)$.

Nuestro autor insiste en que su análisis no buscaba sólo la descripción funcional de un habla, sino «la oposición contrastiva con que se caracteriza cada uno de los niveles» $(\$ 81)$.

Manuel Alvar llevó a cabo en conjunto, entre 1967 y 1972, varios escritos de carácter sociolingüístico, acaso estimulado por la que él estimó que había sido una postura poco comprensiva del prof. Catalán en la $Z R P h$, y asimismo estimulado quizá por el trabajo que sabía desarrollaba entonces en Barcelona Antonio Badía.

No obstante - y mientras tanto- Julián Marías se refirió en su discurso de recepción en la Academia a La realidad histórica y social del uso lingüístico (1965). El autor aplicaba al idioma conceptos de Ortega y Gasset, y podía enunciar así: «La lengua es un uso [...]. Los usos son vigencias que ejercen presión sobre nosotros y nos obligan a ajustar nuestra conducta a ellas o bien a resistirlas, a discrepar. [... El objeto de la descripción lingüística] es en buena medida un repertorio de normas: aquellas que constituyen la gran vigencia que llamamos una lengua». Creemos por nuestra parte que el empleo de algunos de estos conceptos orteguianos, puede ciertamente ayudarnos a saber exponer más exactamente o con mayor propiedad los hechos de la vida del idioma.

$* * *$

En efecto el informe de Alvar recogido en Estructuralismo, geografía lingüistica y dialectología actual decía respecto de Barcelona: «Aquí la complejidad se acrecienta con la inmigración masiva de gentes de habla castellana [... Badía...] investiga la lengua de los hablantes, los niveles sociales (edad, sexo, instrucción) en que se usa, el empleo de una u otra con interlocutores alófonos, valoración de la otra lengua, etc.». Tal investigación se hallaba por entonces inédita, pero Alvar estimaba que tras haberse hecho, se estaba propiamente «en el momento de comenzar el estudio del habla de Barcelona».

Francesc Vallverdú ha estimado por su parte (Anthropos, . $^{\circ} 81,1988$, dedicado por entero al lingüista catalán) que ciertamente con el volumen La llengua dels barcelonins, su autor entraba en la Sociolinguística, aunque antes de esa fecha A. Badía publicó textos de materias que luego se integraron en la Sociolinguística (como - cabe añadir- les ha ocurrido a otros investigadores, según queda visto).

El propio Antonio Badía piensa por su lado que la nueva Sociolingüística (o sea, la Sociolingüística propiamente dicha tal como la entendemos en nuestros días) surge con la aparición en 1953 del conocido libro de U. Weinreich Lenguas en contacto; en su discurso inaugural del año académico 1976-77 («Ciencia y pasión en la lingüística catalana moderna»), aludirá así retrospectivamente a «la introducción más bien tardía de la Sociolinguística entre nosotros» y a cómo «en poco más de diez años la hemos visto constituida: pujante, solvente, comprometida». 
Badía ha definido esta clase de estudios: por ej. en la conferencia «Lenguas en contacto [...] (con especial aplicación al catalán)» (en el volumen coordinado por Lapesa Comunicación y lenguaje, Madrid, Karpos, 1977; la conferencia es tres años anterior, y tuvimos ocasión de asistir a ella personalmente), nuestro autor establece que la disciplina «se interesa por el comportamiento de la lengua en la sociedad». Cualquiera que haya leído de la materia sabe que los estudios sociolinguísticos atienden mucho a la incidencia de lo social - variable independiente - en lo idiomático — variable dependiente-; por eso nuestro autor precisa y concreta más, y enuncia varios de los capítulos de la materia: 1. Lenguas en contacto. 2. «Extensión de la lengua común o estándar a expensas de modalidades regionales o locales». 3. «Tipos de lengua según niveles socioculturales o según las situaciones en que se encuentran los hablantes, fórmulas de tratamiento, etc.». Este último campo de trabajo supone el análisis diastrático, y es el que más han estimado algunos estudiosos en tanto específicamente sociolinguístico. Bien vemos cómo al igual que Catalán y que Alvar, Antonio Badía habla del estudio de los «niveles socio-culturales» en la traza diseñada anteriormente por Rona.

La aludida monografía en torno a La llengua dels barcelonins (Barcelona, Edicions 62,1969 ) trataba demoradamente de la propia encuesta, y se ocupaba de manera expresa ( $\$ \S 80-93)$ del catalán y el castellano en tanto lengua habitual de unos u otros habitantes de la ciudad; consta así el dato que de 223 encuestados mediante visita personal, $141(63,2 \%)$ manifestaban tener como idioma habitual el catalán, y $82(36,8 \%)$ el castellano.

Pero digamos también que poco antes de la conferencia «Lenguas en contacto» mencionada, en 1972, Badía publicó en la $R L R$ a la que está tan vinculado como romanista (tomo 36) el estudio «Langue et société dan le domaine linguistique catalan, notamment à Barcelone».

Julián Marías habló de catalán y castellano en una Consideración de Cataluña que hizo (Barcelona, Aymá 1966), y sus páginas las analiza luego Francesc Vallverdú en el volumen Sociología y lengua en la literatura catalana (Madrid, Ed. Cuadernos para el Diálogo, 1971). Otro volumen serio que ha de verse de estos años es el de Rafael Ll. Ninyoles, Idioma y poder social, que refunde dos obras anteriores (Madrid, Tecnos, 1972). Etc.

B)

El prof. Francisco Gimeno ha hecho referencia en varias ocasiones a algunos escritos nuestros juveniles con tono que ha deseado ser generalmente reprobatorio - aunque las desestimaciones no nos han alcanzado sólo a nosotros-; como lo ha hecho con insistencia, deseamos exponer algunos hechos objetivos que deben tenerse en cuenta. Lo hacemos por supuesto con caballerosidad personal, con amistad, y con serenidad científica.

La principal desestima de nuestro colega ha recaído en las Lecturas de Sociolingüística que preparamos a mitad de los años setenta (Madrid, EDAF, 1977); en Contribuciones al estudio de la lingüística hispánica. Homenaje al 
profesor Ramón Trujillo (Barcelona, Montesinos, 1977, II), sentencia excluyentemente: «Lecturas son, no cabe duda, pero me pregunto ¿de utilidad y estímulo para conocer y divulgar la sociolingüística? Lo dudo. [...] El título y la selección de la obra [...] parecen incentivar la confusión y equívoco» (digamos al margen que al no haber podido ver pruebas de imprenta, nuestro trabajo en esas Contribuciones al estudio... tiene pasajes poco inteligibles).

Luego otra vez, y de manera muy pública y con la misma cierta violencia, manifestó en un Congreso filológico internacional respecto de las Lecturas...: «Me pregunto si son útiles y ofrecen estímulo para conocer y divulgar la sociolinguiística . [...] El título y la selección de la obra que nos ocupa parecen incentivar la confusión y el equívoco».

En realidad las reticencias hacia mi texto ya las había expresado antes $\mathrm{H}$. López Morales, quien había escrito que tanto mi volumen como otro de Garvin y Lastra y alguno más «dejaba insatisfechos a los lectores».

Gimeno tiene manifestada por escrito su «eterna gratitud» a sus maestros don Manuel Alvar y don Humberto López Morales: su reticencia prolonga por tanto y viene sugerida por la de don Humberto López; por mi parte debo decir que me formé en la Universidad de Granada con Manuel Alvar (1967-1968), que le debo mi incorporación al profesorado universitario, y que he leído constantemente sus publicaciones, como él mismo me reconocía siempre: el interés por las cuestiones sociolingüísticas de él me viene, aunque sea materia sobre la que dejé en parte de leer y dejé de publicar hace ya años: ahora no obstante me resultará materia más cercana, al haber reingresado no hace mucho en el cuerpo de profesores de «Lengua Española».

Debo aclarar ante don Humberto López y ante mi compañero F. Gimeno y ante el lector imparcial-que las Lecturas de Sociolingüística están hechas en una editorial ajena por completo a lo filológico, y que hubieron de prepararse sin haberse podido plantear siquiera la consecución de algunos permisos para traducir textos (ya que no había presupuesto alguno para tales traducciones), y con la decisiva limitación de poder acudir sólo a fragmentos de personas conocidas y amigas a las que el profesor no numerario de veintitantos años que era yo recababa su asentimiento conforme - en el caso de algún autor lo recabé a sus herederos, o a sus editoriales; conservo en este sentido una bella carta de Diego Catalán-. Mi volumen se publicó sólo gracias a la bondadosa disponibilidad de los autores, y a la estricta confianza personal que en mí depositaron los editores.

La poderosísima editorial Planeta anunció por los mismos años un tomo semejante que fue encargado además a autoridad relevante, pero el proyecto hubo de quedar abandonado - según se me dijo de forma expresa - ante la carencia de permisos para poder traducir algunos artículos imprescindibles, y ante otras dificultades que mi experiencia de recopilador me dice que había que superar. Mi libro se hizo pues en condiciones intelectuales un tanto precarias, pero el empeño juvenil que puse en él lo hizo salir adelante; me consta por los muchos años (36) que llevo en la profesión, que su misma presencia no fue bien acogida cuando otros intentos parecían frustrarse (hay colegas que me testificaron que ese malestar verosímilmente se aumentó además, al ocupar yo pronto una cátedra ma- 
drileña): las circunstancias editoriales y académicas objetivas ajenas a mí parecían ponerse en contra de un examen completamente incontaminado de mi trabajo.

Parafraseando el decir clásico tan repetido por Ortega, yo hice al componer el volumen lo que pude dentro de los permisos de edición a que me fue dado acceder; Fortuna hizo lo que quiso. ¿Que más hubiera deseado que incorporar alguno de los capítulos que sí pudieron editar Garvin y Lastra!

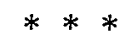

Mi compañero F. Gimeno tiene publicado un volumen sobre Dialectología y Sociolingüística españolas (Universidad de Alicante, $1990^{2}$ ). Es un texto que parece proceder de su Memoria de opositor: desde luego presenta inequívocamente algunos de los rasgos de este género de escritos.

Vamos a comparar el contenido de mis Lecturas... con asimismo el contenido del libro de Gimeno, y veremos que aunque él tiene a mi volumen por inútil y fuente de confusión, de hecho él se ocupa en buena medida de los mismos autores y exactamente de los mismos fragmentos. No somos fuente de confusión los dos: creo que acertamos los dos; para él al menos mi trabajo no ha tenido inutilidad ni le ha supuesto una falta de estímulo.

1) Yo selecciono un fragmento de I. Iordan sobre Hugo Schuchardt; Gimeno remite exactamente al mismo pasaje en la p. 74 de su libro.

2) Las Lecturas... acogen unas páginas de don Vicente García de Diego; son con toda coincidencia las mismas citadas por mi colega en su p. 119, quien además reproduce a la letra formulaciones de G. de Diego. Don Vicente no había dado una versión tan completa de su texto en la primera edición de su Dialectología; por eso y conscientemente, lo seleccionado procedía de la segunda.

Cabe decir asimismo que tales páginas del relevante dialectólogo habían pasado un tanto inadvertidas hasta que quedaron subrayadas por su presencia en las Lecturas...; no es fácil encontrarlas citadas por los sociolingüistas antes de la reproducción a la que aludimos, y no recordamos que primeros dialectólogos como Zamora, Alvar, etc., las aludiesen nunca; recordamos en cambio cómo el prof. Ángel Alonso-Cortés (él acaso lo haga también) nos manifestó que tales páginas de don Vicente fueron comentadas en la Facultad de Letras de Valladolid justamente al quedar rescatadas por mí. Desde luego Gimeno las menciona tras haberlas destacado yo.

3) El libro de Lecturas... recoge el concepto de «norma» de Coseriu, y lo hace en tanto contribuye a lo que planteamos expresamente como un marco teórico de referencias para la Sociolingüística; en efecto las invariantes idiomáticas subfuncionales que dependen de la estratificación social son hechos de norma en el sentido del lingüista rumano: creemos esta incorporación al volumen científicamente justificada. Tanto Gimeno como Manuel Alvar, etc., han mencionado unos u otros textos de Coseriu al tratar de Sociolingüística. 
4) Lo sociolingüístico y en sentido amplio lo dialectal nada más adquiere sentido que en una concepción de la lengua o el idioma como archisistema; recogemos así en nuestro libro («La lengua como pluralidad de sistemas») unas páginas de manuales entonces recientes en las que se ilustra tal idea de la lengua en tanto en realidad archisistema. Para facilitar el proceso editorial, no acudimos a un segundo texto de Coseriu que hubiese venido muy bien a este propósito ya le habíamos pedido permiso para uno-, y sí a la exposixión que se encontraba en un par de manuales.

Tanto la idea de «norma» como la de "archisistema»—según decimosresultan de necesario conocimiento para abordar los estudios dialectales y sociolingüísticos: de esta manera nos propusimos introducirlas en la parte general que en nuestro volumen se rotula «Marco teórico de referencias».

5) Lecturas... lleva además unos fragmentos de Diego Catalán; Gimeno remite (p. 120 de su libro) exactamente —en parte-a los mismos pasajes.

Además el prof. Catalán ha debido estimar lo suficientemente acertada mi elección de unas páginas suyas, como para recoger luego en uno de sus volúmenes tal selección en tanto una contribución suya exenta: nos alegra de veras, dada su muy alta autoridad intelectual en filología y dialectología (D. Catalán es - en nuestra opinión, y desde hace unos años-, el mayor filólogo vivo de habla castellana); vid. su volumen El español. Orígenes de su diversidad, Madrid, $\mathrm{Pa}$ raninfo, 1989, cap. 11.

6) Recojo en las Lecturas... dos fragmentos de Manuel Alvar y de H. López Morales; Gimeno no sólo se reconoce deudor de ellos y los tiene por sus maestros, sino que los sigue de cerca: por ej. escribe Alvar que

la misión de un método no acaba con la aparición de otro, sino que puede coexistir con él y aun reelaborarse dentro de sus propios condicionamientos.

Su discípulo y colega nuestro lo sigue - según decimos- de cerca:

el cometido de un método no acaba con la aparición de otro, sino que puede coexistir con él, y aún reelaborarse dentro de sus propias limitaciones (p. 116).

En otra ocasión Alvar escribió, en alusión al ALEA:

Gregorio Salvador quedó incorporado a las tareas colectoras en 1953; todavía después (1956), Antonio Llorente pasó a engrosar este restringido equipo. Los 230 puntos seleccionados fueron visitados en seis años, y aún se llevaron a cabo encuestas secundarias y en alguna localidad se repitieron las preguntas con informadores diferentes (hombre y mujer; sujetos cultos e ignorantes).

F. Gimeno expone:

Al año siguiente [1953] quedó incorporado G. Salvador a las tareas colectoras, y tres años después $\mathrm{A}$. Llorente pasó a engrosar el restringido equipo. Los 230 puntos seleccionados fueron visitados en seis años, e incluso se llevaron a cabo 
encuestas secundarias, y en alguna localidad se repitieron las preguntas con informadores diferentes (hombre y mujer; cultos y analfabetos) (pp. 89-90).

No parece verosímil - por otra parte-que mi compañero piense que yo confundo a los lectores con los dos fragmentos de sus maestros.

7) Incorporo a mi volumen un conocido artículo de G. Salvador —quizá su mejor artículo-: es exactamente el mismo al que él remite en su p. 119.

8) Asimismo figura en las Lecturas... un autor también atendido por Gimeno: G. de Granda; por mi parte no creo que esté fuera de lugar en una obra como la que compuse, un artículo que se titula «Diatopía, diastratía y diacronía de un fenómeno fonético dialectal en el occidente de Colombia».

9) En fin figura en mi compilación - y la honra - buena parte del texto de don Ramón Menéndez Pidal «Sevilla frente a Madrid». No sólo se trata de una de las monografías pidalinas mayores, sino que ya un lector tan incansable y tan agudo como el inolvidable Víctor Sánchez de Zavala señaló en uno de sus libros tal trabajo de don Ramón, en tanto una magnífica ilustración de cómo las circunstancias externas históricosociales inciden en el sistema idiomático. No creo que se equivocasen ni en su planteamiento ni en su estimación lo mismo Menéndez Pidal que Sánchez de Zavala; por mi parte creo que tampoco me equivoqué al rescatar en parte un artículo de don Ramón que luego no sabemos reproducido nunca.

$$
* * *
$$

Por lo demás la manera de trabajo de mi compañero y mía resultan distintas: sin duda nuestra respectiva sensibilidad filológica es diferente, lo cual es legítimo, además de inevitable. Él por ej. parece valorar a Juan Miguel Lope Blanch menos de lo que yo suelo hacerlo en el conjunto de mis modestos trabajos; por contra menciona escritos que a nosotros nos merecen menor fiabilidad, como los de V. Lamíquiz - a los que no solemos acudir-. Prescinde del escrito capital de Rona acerca de la problemática metodológica de la dialectología, y no parece haber accedido directamente tampoco a algún texto de relieve de García de Diego.Trabajamos con diferentes concepciones y de distinta manera.

También da la ficha a veces de libros y artículos que en el conjunto de Dialectología y Sociolingüística españolas a nosotros nos parece que no hubiera sido necesario mencionar: así el libro de don Amado Castellano, español, idioma nacional. En un contexto en el que se alude al ALEICan nosotros personalmente no hubiésemos mencionado un artículo de M. Alvar ajeno al Atlas como el rotulado «Sociología en un microcosmos lingüístico»; por igual es ajeno al $A L P I-\mathrm{y}$ nosotros no lo hubiésemos citado cuando se trata de él- el libro de A. M. Espinosa, hijo, Arcaísmos dialectales (1935). En todo caso, esto no posee mayor importancia: se trata de meros ejemplos de distinta sensibilidad profesional.

Etc. 
Se observa pues cómo los autores tenidos en cuenta por mí son los mismos a los que mi crítico F. Gimeno asimismo apela en buena medida; los mismos o algunos otros vienen avalados además por valoraciones de lingüistas de autoridad.

La imagen de lo sociolingǘstico de Francisco Gimeno y la mía son muy semejantes en las dos obras a las que nos referimos, y esos nuestros dos volúmenes lo prueban suficientemente; sus desestimaciones no las tengo por técnicamente justas.

En definitiva las Lecturas de Sociolingüística las hice con los medios que estaban a mi alcance; ni siquera la poderosísima Editorial Planeta pudo sacar adelante un volumen ariálogo anunciado. Esas Lecturas pusieron en circulación textos adecuados, pues el mismo F. Gimeno los avala haciendo uso de ellos con posterioridad; están avalados asimismo por la cita que de los más importantes hizo nuestro común maestro Manuel Alvar, de quien yo sí fui alumno y colaborador de cátedra directo.

Ni el libro de mi colega ni el mío me parecen desorientadores, aunque estoy seguro de que con la actual edad y madurez sabríamos mejorarlos uno y otro de nosotros. Digamos en todo caso la verdad: mi compañero critica que se citen los mismos textos que él menciona cuando lo ha hecho años antes un compañero y amigo (en la $R E L$ ya se me acusó falsamente de algo en parte parecido).

En todo caso el daño hacia mí queda hecho, pues no siempre quienes vean sus alusiones a mi trabajo profesional verán acaso estos párrafos en los que intento razonar cómo F. Gimeno critica en mí —como digo- lo que él mismo tiene por bueno años más tarde si lo hace él. Las alusiones de su maestro don Humberto López parecen haberle desorientado, dicho quede todo con corrección y amistad pero con sentido de los hechos reales.

Hay un anuncio radiofónico en el que se dice que si en algunas personas no se ve su trabajo, ni sus amigos, ni su futuro, ni su familia, sólo se ve entonces lo que se quiere ver: un inmigrante. Análogamente (y dicho en general, sin alusión a caso concreto alguno), si en un profesor no se ven los datos objetivos de sus actividades profesionales, acaba viéndose sólo y nada más que lo que se quiere percibir, o lo que se desea percibir aunque no sea muy verdadero para contrarrestar algún paso suyo adelante. 